\title{
Effect of Inhaled Nitrogen Oxide on the Plasma Concentration of Cytokines and Endogenous Nitrogen Oxide
}

\author{
Vladimir Vladimirovich Estrin, Marina Gaevna Pukhtinskaya* \\ Department of Anesthesiology and Resuscitation, State Medical University, Rostov-on-Don, Russia
}

\author{
Email address: \\ puhmar@mail.ru (M. G. Pukhtinskaya) \\ ${ }^{*}$ Corresponding author
}

\section{To cite this article:}

Vladimir Vladimirovich Estrin, Marina Gaevna Pukhtinskaya. Effect of Inhaled Nitrogen Oxide on the Plasma Concentration of Cytokines and Endogenous Nitrogen Oxide. American Journal of Pediatrics. Vol. 7, No. 2, 2021, pp. 62-67. doi: 10.11648/j.ajp.20210702.15

Received: March 22, 2021; Accepted: April 7, 2021; Published: April 20, 2021

\begin{abstract}
Rationale. The nitrogen oxide molecule (NO) is a fundamental factor of the anti-infectious resistance of an organism. Research objective. To evaluate the effectiveness and safety of the prevention of sepsis by the inhalation of nitrogen oxide (iNO) in newborns with respiratory pathology on artificial pulmonary ventilation. Methods. Controlled, randomized, blind clinical trial included 97 newborns with respiratory pathology for artificial pulmonary ventilation. Patients received standard intensive therapy. The main group $(\mathrm{n}=44)$ received inhaled nitrogen oxide. The control group $(\mathrm{n}=53)$ did not receive inhaled nitrogen oxide. On Days 1, 3, and 20, the plasma concentrations of IL-1ß, IL-6, IL-8, TNF- $\alpha$, G-CSF, s-Fas, FGF, and nitrogen oxide were measured by capture ELISA. Results. Inhaled nitrogen oxide as a part of intensive care decreased the rate of sepsis development, the duration of mechanical ventilation, and the period of hospitalization. It provided a tendency towards a decrease in the rate of lethal outcomes and reduced cytokine aggression. Conclusions. Inhaled nitrogen oxide in standard intensive care effectively and safely prevented the development of sepsis in newborns with respiratory pathology on artificial lung ventilation. A decrease in the concentration of pro-inflammatory cytokines, including IL-6, against the background of nitrogen oxide inhalation, confirmed the possibility of using inhaled nitrogen oxide as a therapy for COVID-19.
\end{abstract}

Keywords: Sepsis, Newborn, Nitrogen Oxide Inhalation

\section{Introduction}

A constant increase in the rate of development and a high lethality make sepsis remain one of the most fundamental problems of medicine and humanity, in general [1].

The lowest tolerance to the development of bacterial complications is observed in newborns on artificial pulmonary ventilation, which is determined by a number of such factors as the severity of the condition due to the primary or comorbid diseases, the peculiarities of the functioning of the immune system, the necessity of the invasive methods of diagnostics and laboratory monitoring, the changes in the etiological structure of the infective microorganisms with the appearance of strains multi-resistant to the majority of antibiotics used in clinical practice $[1,2]$.

These conditions indicate the necessity of the development of new methods of prevention and intensive therapy for bacterial complications because of a high rate of lethality in neonates with sepsis shows that conventional treatment plans are insufficient.

Inhaled nitrogen oxide (iNO) occupies a certain place in the therapy for respiratory pathology of newborns considering the uniqueness of its activity, effectiveness, and safety confirmed by numerous studies [3-9].

Nitrogen oxide (NO) is a universal intercellular messenger that is involved in the processes of proliferation, apoptosis of lymphocytes and monocytes, phagocytosis, and the activation of the complement system. It is one of the most important factors in the anti-infectious resistance of the immune system of an organism [9]. A molecule of nitrogen oxide is multifunctional because it takes part in the intercellular and intracellular signaling by changing the cytokine milieu of the immunocompetent cells $[10,11]$.

Within the last decade, there has been an increase in the 
publications of studies dedicated to the role of apoptosis of immunocompetent cells in the development of bacterial complications in newborns [12].

Cytokines are known to be biologically active endogenous factors that determine the development of the inflammatory process $[13,14]$. Uncontrolled hyperproduction of antiinflammatory pro-apoptotic cytokines, a decrease in the plasma concentration of growth, proliferative, and antiapoptogenic factors that lead to the development of catastrophic cytokine disbalance represent a significant part of the pathogenesis of the activation of apoptosis of immunocompetent cells and the development of bacterial complications [15].

The significance of the molecule of nitrogen oxide in the pathogenesis of some immune processes allows the authors to assume the presence of immunoprotective properties in inhaled nitrogen oxide [16-19].

Clinical verification of immunoprotective properties of inhaled nitrogen oxide will allow the specialists to expand the range of its indications in the therapy for critical conditions in newborns on the artificial pulmonary ventilation, in particular, for the prevention of bacterial complications.

The lack of publications on such studies determines the rationale for the present study.

Research Objective. The study was aimed to evaluate the effectiveness and safety of the prevention of sepsis by the inhalation of nitrogen oxide in newborns with respiratory pathology on artificial pulmonary ventilation.

\section{Materials and Methods}

\subsection{Study Design and Patients}

\subsubsection{Ethics}

From 2018 to 2019, 97 full-term newborns with respiratory pathology on artificial pulmonary ventilation that were delivered from municipal and regional maternity hospitals were examined at the Department of Resuscitation of the State Medical University (Rostov-on-Don, Russia). All the examined patients were included in the study.

The controlled randomized clinical study was approved by the local ethical and bioethical committee of the State Medical University (protocol 18/1 dated November 2, 2018 and No. 20/1 dated November 2, 2018).

Patients were included in the study after the written permission of their parents or legal representatives. The text of the permission and the protocol of the study were written according to the Helsinki Declaration 1975 (with amendments dated 2005), Federal Law No. 323-FZ dated November 21, 2011 "The Basics of the Healthcare of Citizens in the Russian Federation", basis of the Russian legislation "Healthcare of Citizens and Guidelines on Clinical Practice in the Russian Federation" (Decree of the Ministry of Health of the Russian Federation No. 266 dated July 19, 2003, Decree of Federal Service for Surveillance in Healthcare No. 2325-Pr/06 dated October 17, 2006).

\subsubsection{Intervention Details}

The criteria of the study inclusion were:

a. admission to the Department of Resuscitation on artificial pulmonary ventilation not later than 2 days after the birth;

b. the lack of clinical signs of bacterial infection at the admission;

c. diagnosed respiratory pathology (meconium aspiration syndrome, unspecified respiratory disorders, secondary lung atelectasis);

d. gestational age at birth more than 37 weeks;

e. body weight at birth more than $2500 \mathrm{~g}$;

f. Criteria of non-inclusion in the study:

g. suspected or verified congenital abnormalities of the respiratory tract or lungs;

h. verified complex congenital heart disease;

i. severe left ventricular dysfunction;

j. pneumothorax;

k. suspected or verified chromosome abnormality or genetic aberration.

The patients included in the study were randomized into two groups by the method of envelope: main group $(n=44)$ and control group $(n=53)$.

Patients from both groups received conventional intensive therapy. Apart from conventional therapy, patients from the main group received inhaled nitrogen oxide $(10 \mathrm{ppm})$ for 48 hours with a further decrease of the dose of inhaled nitrogen oxide to $5 \mathrm{ppm}$ for 5 hours with $1 \mathrm{ppm}$ pace. Inhaled nitrogen oxide was given at a dose of $1 \mathrm{ppm}$ for 1 hour with further discontinuation at the background of dynamic control of the vital functions and hemoglobin content in the blood.

The control group included newborns that received only conventional intensive therapy.

In the present study, the dose of inhaled nitrogen oxide and the duration of the inhalation were defined according to the published scientific data, existing clinical recommendations, and the results of the performed studies [20-22].

The choice of a relatively low dose of inhaled nitrogen oxide and short exposition was made considering the dualistic properties of this gas transmitter depending on the concentration and scientific data which show that low doses of inhaled nitrogen oxide have a similar positive effect to high doses of $40 \mathrm{ppm}$ and higher [23, 24]. Due to the "offlabel" status of inhaled nitrogen oxide in Russia, its inhalations were indicated to patients after the preparation of the required documentation.

In the present study, the inhalations of nitrogen oxide were performed along with high-frequency ventilation or traditional lung ventilation by means of feeding gas to the contour of patients via a connector by the apparatus of a dosed and control feeding of nitrogen oxide "Pulmonox mini" "Messer II NO Therapeutics" (Austria). The concentrations of $\mathrm{NO}$ and $\mathrm{NO}_{2}$ were controlled in the room for iNO therapy (NO $<10 \mathrm{ppm}, \mathrm{NO}_{2}<5 \mathrm{ppm}$ ). The gas mixture of $\mathrm{NO}$ and nitrogen with the concentration of $\mathrm{NO}=1000 \mathrm{ppm}$ ("Linde Gaz Rus", OJSC) was used for inhalations. During the inhalations of $\mathrm{NO}$, any changes in the condition of patients 
were fixed: light (any deviations in the condition) and severe (elongation in the period of hospitalization, life-threatening condition).

Criteria of the indication of inhalation nitrogen oxide were: confirmation obtained as a result of randomization;

written consent of parents.

Contraindications to inhalation nitrogen oxide:

methemoglobinemia (congenital or acquired);

Laboratory verified hypocoagulation;

thrombocytopenia less than $50.0 \times 10^{9} / \mathrm{L}$;

intraventricular hemorrhage (3rd-4th degree).

Criteria of preterm discontinuation of the therapy with inhalation nitrogen oxide were:

an increase in the level of methemoglobin in the blood higher than $2.5 \%$;

any life-threatening change in the condition of a patient or a condition that may lead to an elongation of the period hospitalization.

\subsubsection{Assessment and Endpoints}

The main endpoints of the present study were the rate of the development of bacterial complications and unfavorable outcome of the disease, the duration of artificial lung ventilation, and the period of hospitalization in the resuscitation ward. The changes in the plasma concentration of cytokines and endogenous nitrogen oxide in the dynamics of the disease were treated as additional criteria of the evaluation.

A clinical study was performed with the working hypothesis that inhalation nitrogen oxide as a part of conventional intensive therapy decreased the rate of the development of sepsis, rate of lethality, duration of artificial lung ventilation, and period of hospitalization at the Department of Resuscitation.

\subsection{Research Methods}

\subsubsection{Immunological Methods}

At the admission, on Day 3 and 20 of the hospitalization (or at the disease outcome), apart from the standard cliniclaboratory observation and examination, patients from both groups had the plasma concentration of cytokines (IL-1ß, IL6 , IL-8, TNF- $\alpha$, G-CSF, sFas, FGF) and endogenous nitrogen oxide measured by the method of enzyme-linked immunosorbent assay (ELISA, amplifier - horseradish peroxidase) (Biosource, USA; Bender Medsystems, Austria; R\&D Systems, USA; computer counter Multilabel Counter Victor-21420, Finland).

\subsubsection{Statistical Methods}

Digital results obtained from 97 patients were included in the statistical analysis.

The obtained data was evaluated using the methods of variation statistics with the identification of the sample mean, standard deviation, standard error of the mean, confidential intervals, median, and median error.

Statistical analysis was performed in statistical programs: Excel-2007, Statistica-6, package "R". Statistical significance of the differences was evaluated using the Wilcoxon test and Mann-Whitney test.

The risk of the development of neonatal sepsis and the lethal outcome was analyzed by making fourfold tables.

The duration of artificial pulmonary ventilation and hospitalization at the resuscitation unit were evaluated as a function of survival by the Kaplan-Meier plots with the comparison of the results with the Gehan-Wilcoxon test. The correctness of the hypotheses was checked by the FisherIrwin test (at $\mathrm{p}=5 \%$ for two-sided alternative).

\section{Results and Discussion}

The study power was $86.7 \%(\alpha \leq 0.05)$. The therapy with inhalation nitrogen oxide was not discontinued pre-termly in any case. There were zero cases of light or severe unfavorable effects of inhalation nitrogen oxide registered on the newborns.

The lethal outcomes in six patients from the main group were not associated with the performed inhalations, which was confirmed by the results of the path morphological study.

In the main group $(n=44)$, all four patients had sepsis that caused complications to the primary disease. In the control group $(\mathrm{n}=53)$, sepsis was diagnosed in 13 newborns. Statistical check by the Fisher-Irvin exact test for the twosided alternative (Fisher exact, $\mathrm{p}_{1}=0.04 ; \mathrm{p}_{2}=0.05$ ) confirmed the hypothesis that inhalation nitrogen oxide decreased the rate of the development of sepsis.

In the main group $(n=44)$, six patients had a lethal outcome. In the control group $(n=53)$, ten patients had a lethal outcome. Statistical check by the Fisher-Irvin exact test for the twosided alternative (Fisher exact, $\mathrm{p}_{1}=0.37 ; \mathrm{p}_{2}=0.59$ ) did not confirm the hypothesis that inhalation nitrogen oxide decreased the rate of the lethality.

Despite the fact that the lethal outcome was registered in the main group 1.66 times less, the authors can highlight only a tendency towards a decrease in the rate of unfavorable outcomes in the studied population. The obtained data agreed with the results of numerous published clinical studies [25].

Numerical values of the duration of artificial pulmonary ventilation and hospitalization at the Department of Resuscitation in both groups were analyzed as possibilities of the studied outcome (the function of survival) in a certain period by Kaplan-Meier survival analysis with the GehanWilcoxon test.

The median for the transfer of patients to unassisted breathing in the control group was 10 days. In the main group, the median was 5 days ( $p=0.00007$, Gehan-Wilcoxon test). Thus, inhalation nitrogen oxide significantly decreased the duration of artificial pulmonary ventilation.

Half of the patients (median) in the control group were discharged from the resuscitation unit on Day 15, in the main group, on Day 11 ( $\mathrm{p}=0.02$, Gehan-Wilcoxon test). Thus, inhalation nitrogen oxide significantly decreased the duration of hospitalization at the resuscitation unit.

Numerical values of the concentration of the studied cytokines in patients from both groups in dynamics are 
presented in Tables 1 and 2 .

At the admission to the Department, the concentration of cytokines and endogenous nitrogen oxide in plasma in patients from both groups did not differ statistically, which proved the consistency of the studied population.

It should be noted that at the admission to the Department of Resuscitation, newborns with respiratory pathology on artificial pulmonary ventilation had lower plasma concentration of endogenous nitrogen oxide in comparison with umbilical blood of healthy newborns, which agreed with the results of previous studies (Table 2).

Scientific data confirms that deficit of nitrogen oxide is the main cause of endothelial dysfunction, arterial hypertension, atherosclerosis, diabetic angiopathy, myocardial infarction, angina, atherothrombosis, and preeclampsia [26-28]. The results of the present study do not exclude the significance of a low plasma concentration of endogenous nitrogen oxide in the development of bacterial complications. Further studies are needed to clarify this hypothesis.

Table 1. Comparative dynamics of the plasma concentration of cytokines in patients of both groups.

\begin{tabular}{|c|c|c|c|c|c|c|}
\hline \multirow[b]{2}{*}{ Indicators } & \multicolumn{2}{|l|}{ Day 1} & \multicolumn{2}{|l|}{ Day 3} & \multicolumn{2}{|l|}{ Day 20} \\
\hline & $\begin{array}{l}\text { Main group } \\
(n=44)\end{array}$ & $\begin{array}{l}\text { Control group } \\
(\mathrm{n}=53)\end{array}$ & $\begin{array}{l}\text { Main group } \\
(n=44)\end{array}$ & $\begin{array}{l}\text { Control group } \\
(n=53)\end{array}$ & $\begin{array}{l}\text { Main group } \\
(n=44)\end{array}$ & $\begin{array}{l}\text { Control group } \\
(n=53)\end{array}$ \\
\hline TNF- $\alpha, p g / m l$ & 159.54 & 163.43 & $76.55^{*}$ & 114.88 & $32.48^{*}$ & 86.31 \\
\hline Kv $25 \%$ & 138.31 & 147.62 & 65.15 & 95.29 & 11.72 & 72.06 \\
\hline $\mathrm{Kv} 75 \%$ & 180.7 & 179.24 & 87.95 & 134.47 & 53.24 & 100.5 \\
\hline IL-8, pg/ml & 355.04 & 355.88 & $532.36^{*}$ & 924.15 & 177.79 & 211.4 \\
\hline $\mathrm{Kv} 25 \%$ & 335.11 & 327.36 & 505.3 & 904.41 & 124.15 & 138.76 \\
\hline IL-6, pg/ml & 17.67 & 18.16 & $176.89 *$ & 316.42 & 64.94 & 68.89 \\
\hline Kv $25 \%$ & 16.72 & 17.09 & 121.10 & 258.04 & 59.39 & 64.37 \\
\hline Kv $75 \%$ & 18.62 & 19.23 & 192.68 & 374.8 & 70.49 & 73.41 \\
\hline $\mathrm{IL}-1 \beta, \mathrm{pg} / \mathrm{ml}$ & 4.69 & 4.81 & 8.00 & 8.49 & 3.89 & 4.06 \\
\hline Kv $25 \%$ & 4.42 & 4.71 & 7.12 & 7.38 & 2.79 & 3.76 \\
\hline Kv $75 \%$ & 4.77 & 4.99 & 9.07 & 9.60 & 4.99 & 4.37 \\
\hline
\end{tabular}

*Note: The statistical difference of the indicators is justified $(\mathrm{p}<0.05$, Mann-Whitney test)

Table 2. Comparative dynamics of the plasma concentration of cytokines and nitrogen oxide in patients of both groups.

\begin{tabular}{|c|c|c|c|c|c|c|}
\hline \multirow[b]{2}{*}{ Indicators } & \multicolumn{2}{|l|}{ Day 1} & \multicolumn{2}{|l|}{ Day 3} & \multicolumn{2}{|l|}{ Day 20} \\
\hline & $\begin{array}{l}\text { Main group } \\
(n=44)\end{array}$ & $\begin{array}{l}\text { Control group } \\
(n=53)\end{array}$ & $\begin{array}{l}\text { Main group } \\
(n=44)\end{array}$ & $\begin{array}{l}\text { Control group } \\
(n=53)\end{array}$ & $\begin{array}{l}\text { Main group } \\
(n=44)\end{array}$ & $\begin{array}{l}\text { Control group } \\
(n=53)\end{array}$ \\
\hline G-CSF, ng/ml & 1.69 & 1.68 & $2.66^{*}$ & 1.49 & $1.78 *$ & 1.54 \\
\hline $\operatorname{Kv} 25$ & 1.6 & 1.61 & 2.42 & 1.33 & 1.61 & 1.43 \\
\hline $\mathrm{Kv} 75 \%$ & 1.78 & 1.75 & 2.97 & 1.55 & 1.95 & 1.60 \\
\hline sFas, pg/ml & 6580.63 & 6576.65 & $7350.95 *$ & 5028.6 & 5056.8 & 5186.7 \\
\hline $\mathrm{Kv} 25 \%$ & 5.846 .03 & 6153.19 & 6543.27 & 4605.2 & 4191.58 & 4512.50 \\
\hline FGF, pg/ml & 45.11 & 45.26 & $76.11^{*}$ & 59.09 & $126.77 *$ & 73.73 \\
\hline $\mathrm{Kv} 25 \%$ & 41.23 & 42.33 & 71.08 & 55.07 & 116.96 & 62.62 \\
\hline Kv $75 \%$ & 48.93 & 48.15 & 83.14 & 63.11 & 136.58 & 84.91 \\
\hline $\mathrm{NO}, \mu \mathrm{mol} / 1$ & 8.70 & 9.00 & $40.61 *$ & 29.55 & 21.56 & 21.61 \\
\hline Kv $25 \%$ & 7.2 & 8.12 & 39.32 & 28.34 & 21.21 & 20.16 \\
\hline $\mathrm{Kv} 75 \%$ & 9.23 & 9.57 & 42.12 & 32.13 & 22.11 & 22.73 \\
\hline
\end{tabular}

*Note: The statistical difference of the indicators is justified ( $<<0.05$, Mann-Whitney test)

Further statistical analysis confirmed a statistically significant $(\alpha \leq 0.05)$ increase in the concentration of endogenous nitrogen oxide in plasma of patients from the main group by Day 3 with its further decrease to reference limits in the disease outcome (Table 2).

On Day 3, patients from the main group had a plasma concentration of TNF- $\alpha$, IL-8, and IL-6 that were significantly lower than in the control group (Table 1). The obtained data agreed with the results of the previous studies done by the authors on the leading role of these cytokines in the development of the inflammatory reaction of the immune system and the activation of apoptosis of lymphocytes in newborns with respiratory pathology.

The concentration of IL-1 $\beta$ in patients from both groups did not differ, which confirmed the lack of the influence of inhalation nitrogen oxide on the systemic synthesis of this cytokine (Table 1).

Besides, patients from the main group had a significant increase in the concentration of G-CSF, sFas, FGF, and endogenous nitrogen oxide on Day 3-5 in comparison with the control group (Table 2).

In the disease outcome, significantly lower levels of TNF$\alpha$ and significantly higher levels of FGF and G-CSF were observed in these newborns in comparison with newborns that received only standard therapy.

Thus, a comparative analysis of the dynamics of the concentration of cytokines and endogenous nitrogen oxide in patients from both groups revealed a statistically significant 
increase in the concentration of sFas, FGF, G-CSF, endogenous nitrogen oxide and a decrease in the concentration of TNF- $\alpha$, IL- 6 , IL- 8 against the background of inhalations of nitrogen oxide.

The summed resulting values of the interaction of the mentioned cytokines and endogenous nitrogen oxide in plasma in the necessary and sufficient concentrations were represented by an increased activity of the immune system that can resist the development of septic infection when compared with patients that received only standard intensive therapy.

A decrease in the rate of the development of sepsis in patients from the main group was associated with an increase in plasma concentration of nitrogen oxide and cytokines with proliferative-apoptotic properties in patients with a decrease in the systemic synthesis of anti-inflammatory TNF- $\alpha$, IL-8, and IL-6.

Thus, the performed study not only confirmed the effectiveness and safety of the concentration of IL-1 $\beta$ in patients from both groups did not differ, which confirmed the lack of the influence of inhalation nitrogen oxide on the systemic synthesis of this cytokine (Table 1).

Inhalation nitrogen oxide in the prevention of sepsis in newborns with respiratory pathology on artificial pulmonary ventilation but also defined the immune mechanisms of its clinical effectiveness.

\section{Conclusions}

In newborns with respiratory pathology on artificial pulmonary ventilation, inhalation nitrogen oxide as a part of conventional intensive therapy effectively and safely decreases the rate of the development of sepsis, the duration of hospitalization at the Department of Resuscitation, and provides a tendency towards a decrease in the rate of lethality

Inhalation nitrogen oxide decreases systemic synthesis of IL-6, IL-8, and TNF- $\alpha$ by inhibiting cytokine aggression and increases the plasma concentration of growth G-CSF, proliferative FGF, anti-apoptogenic soluble s-Fas, and endogenous nitrogen oxide.

A decrease in the concentration of anti-inflammatory cytokines, including IL-6, against the background of the inhalation of nitrogen oxide confirms the possibility of application of inhalation nitrogen oxide as a part of therapy for COVID-19.

\section{References}

[1] Fleischmann C, Goldfarb DM, Schlattmann P, Schlapbach LJ, Reinhart K, Kissoon N. The global burden of paediatric and neonatal sepsis: a systematic review. The Lancet Respiratory medicine; 2018; 6 (3): 223-30.

[2] Charles E, Hunt KA, Harris C, Hickey A, Greenough A. Small for gestational age and extremely low birth weight infant outcomes. $J$ Perinat Med; 2019; 47: 247-51. https://doi.org/10.1515/jpm-2018-0295. Search in Google Scholar
[3] Solov'eva AG, Kuznetsova VL, Peretyagin SP, Didenko N., Dudar AI. The Role of Nitric Oxide in Free-radical Oxidation Processes. Bulletin of the Russian Military Medical Academy; 2016; 53 (1): 228-233.

[4] Greenough A, Decobert F, Field D, et al. Inhaled nitric oxide (iNO) for preventing prematurity-related bronchopulmonary dysplasia (BPD): 7-year follow-up of the European Union Nitric Oxide (EUNO) trial. J Perinat Med. 2020; Sep 7:/j/jpme.ahead-ofprint/jpm-2020-0164/jpm-2020-0164.xml.

[5] Barrington KJ, Finer N, Pennaforte T. Inhaled nitric oxide for respiratory failure in preterm infants. Cochrane Database Syst Rev. 2017b; Jan 3; 1: CD000509.

[6] Barrington KJ, Finer N, Pennaforte T, et al. Nitric oxide for respiratory failure in infants born at or near term. Cochrane Database Syst Rev. 2017a Jan 5; 1: CD000399.

[7] Wang X, Li B, Ma Y, et al. Effect of NO inhalation on ECMO use rate and mortality in infants born at or near term with respiratory failure. Medicine (Baltimore). 2019; 98 (41): 7139.

[8] Siefkes HM, Lakshminrusimha S. Management of systemic hypotension in term infants with persistent pulmonary hypertension of the newborn: an illustrated review. Arch Dis Childhood Fetal Neonatal Ed. 2021. doi: 10.1136/archdischild-2020-319705. [Epub ahead of print].

[9] Indo H. P. et al. A mitochondrial superoxide for oxidative stress diseases and aging. J. Clin. Biochem. Nutr. 2015; 1 (56): $1-7$.

[10] Yu B, Ichinose F, Bloch DB, Zapol WM. Inhaled nitric oxide. Br. J. Pharmacol. 2019; 176 (2): 246-255. Published online 2018 Nov 16. doi: 10.1111/bph.14512.

[11] Novikov VE, Levchenkova OS, Pozhilova EV. Mitochondrial synthase of nitric oxide and its role in the mechanisms of cell adaptation to hypoxia. Reviews of clinical pharmacology and drug therapy; 2016; 14 (2): 38-46.

[12] Ahmed MS, Giesinger RE, Ibrahim M, Baczynski M, Louis D, McNamara KP, et al. Clinical and echocardiography predictors of response to inhaled nitric oxide in hypoxic pre-term neonates. J Paediatr Child Health. 2019; 55: 753-61. doi: 10.1111/jpc. 14286 .

[13] Pukhtinskaya M, Estrin V. Clinical and diagnostic value of plasma concentration of nitrogen oxide in newborn with respiratory disease. Critical Care; 2018; 22 (1): 018.

[14] Christmas P. Role of cytochrome P450s in inflammation. Adv Pharmacol. 2015; 74: 163-92. doi: 10.1016/bs.apha.2015.03.005.

[15] Cavalcante GC, Schaan AP, Cabral GF, Santana-da-Silva MN, Pinto P, Vidal AF, Ribeiro-Dos-Santos Â. A Cell's Fate: An Overview of the Molecular Biology and Genetics of Apoptosis. Int J Mol Sci. 2017; 4133 (2019).

[16] Savchenko AA, Borisov AG, Zdzitovetsky DE, Gvozdev II. Cytokine regulation of respiratory burst in blood neutrophils for prediction of abdominal sepsis in patients with extended purulent peritonitis. Medical Immunology; 2016; 18 (5): 475482.

[17] Deppisch C, Herrmann G, Graepler-Mainka U et al. Gaseous nitric oxide to treat antibiotic resistant bacterial and fungal lung infections in patients with cystic fibrosis: a phase I clinical study. Infection. 2016; 44: 513-520. 
[18] Jamaati H, Mortaz E, Pajouhi Z et al. Nitric Oxide in the Pathogenesis and Treatment of Tuberculosis. Front. Microbiol. 2017; 8: 2008.

[19] Sekar K, Szyld E, McCoy M, Wlodaver A, Dannaway D, Helmbrecht A, et al. Inhaled nitric oxide as an adjunct to neonatal resuscitation in premature infants: a pilot, double blind, randomized controlled trial. Pediatr Res. 2020; 87: $523-$ 8. doi: 10.1038/s41390-019-0643-x.

[20] Vieira F., Makoni M, Szyld E, Sekar K. The Controversy Persists: Is There a Qualification Criterion to Utilize Inhaled Nitric Oxide in Pre-term Newborns? Front. Pediatr., 31 March 2021 / https://doi.org/10.3389/fped.2021.631765.

[21] Burov AA, Grebennikov VA, Krychko DS. Draft clinical protocol for diagnosis and therapy of persistent pulmonary hypertension in newborns. Neonatology: news, opinions, training; 2014; 1 (3): 145-161.

[22] Hayes, Inc. Hayes Directory Review of Reviews. Inhaled nitric oxide for the treatment of respiratory failure in preterm newborns. Lansdale, Pa: Hayes, Inc.; 2018.

[23] Manja V, Guyatt G, Lakshminrusimha S, Jack S, Kirpalani H,
Zupancic JAF, et al. Factors influencing decision making in neonatology: inhaled nitric oxide in pre-term infants. J Perinatol. 2019; 39: 86-94. doi: 10.1038/s41372-018-0258-9.

[24] Finer NN, Barrington KJ. Nitric oxide for respiratory failure in infants born at or near term. Cochrane Database Syst. Rev; 2006; 18 (4) CD000399.

[25] Ballard RA, Truog WE, Cnaan A. Inhaled nitric oxide in preterm infants undergoing mechanical ventilation. N. Engl. J. Med.; 2006; 355: 343-353.

[26] De Nadai C, Sestili P, Cantoni O, Lièvremont JP, Sciorati C, Barsacchi R. Nitric oxide inhibits tumor necrosis factor-alphainduced apoptosis by reducing the generation of ceramide. Proc. Natl. Acad. Sci USA; 2000; 97 (10): 5480-5485.

[27] Alexandrovitch US, Vizisnov KV. Acute respiratory distress syndrome in pediatric practice. Messenger of intensive therapy; 2014; 3: 23-29.

[28] Boytsov EV, Bialashova MA, Ovsyannikov DU. Modern insights into interstitial lung diseases in children. Journal of the Russian Academy of Medical Sciences; 2015; 70 (2): 227236. 